\title{
Aberrant left main coronary artery induced asymptomatic heart failure
}

\author{
Bankim Patel ${ }^{* 1}$, Aravindan Jeyarajasingam ${ }^{2}$, Kunal Patel ${ }^{2}$, Rupen Patel ${ }^{3}$, Daniel Benatar ${ }^{2}$ \\ ${ }^{1}$ Ross University School of Medicine, Dominica, USA \\ ${ }^{2}$ Mount Sinai Hospital Internal Medicine Residency Program Chicago, IL, USA \\ ${ }^{3}$ East Carolina University/Brody School of Medicine, Greenville, North Carolina, USA
}

Received: January 10, 2016

DOI: $10.5430 /$ crim.v3n4p69
Accepted: August 31, $2016 \quad$ Online Published: October 7, 2016

URL: http://dx.doi.org/10.5430/crim.v3n4p69

\begin{abstract}
We report a case of a malignant course of left main coronary artery in a patient presenting with sudden onset chest pain and shortness of breath. The patient is a 44-year-old African American male with a past medical history of hypertension, diabetes mellitus type 2 as well as dyslipidemia presented to the emergency department with non-exertional chest pain radiating to the left arm and shortness of breath. A coronary angiography and CT angiography (CTA) of heart was performed and it demonstrated an aberrant malignant course of the left main coronary artery coming from the right coronary ostium and coursing between the aorta and pulmonary artery. The left ventricular dysfunction was thought to be a consequence of this malignant course. Cardiothoracic surgery was consulted which determined the need for CABG. The incidence of coronary anomalies and patterns in a series of 1,950 angiograms was determined to be $5.64 \%$ with the left main coronary artery (LMCA) arising from the right sinus in $0.15 \%$ of the angiograms Diagnostic approach for malignant coronary arteries involves coronary angiography and cardiac CT. A widely accepted treatment approach for left main coronary arteries originating from the right sinus is through surgical repair. Our case urges the clinician to expand the differential diagnosis in young to middle age patient presenting with chest pain. In addition, our case reinforces the concept of the detrimental impact of malignant left coronary arteries on cardiac function. This should prompt the physician to consider coronary anomalies as a possible differential diagnosis as part of the evaluation and management of these patients.
\end{abstract}

Key Words: Coronary artery, Heart failure, Aberrant coronary artery, Sudden cardiac death, Cardiac catheterization

\section{Case presentation}

The patient is a 44-year-old African American male with a past medical history of congestive heart failure, hypertension, diabetes mellitus type 2, nonischemic cardiomyopathy presented to the emergency department with non-exertional chest pain radiating to the left arm and shortness of breath. The symptoms were present for one day duration. The pain was aggravated by deep inspiration, lasted for several minutes, and relieved without therapy. He denied any symptoms of heart failure including orthopnea, paroxysmal nocturnal dyspnea, lower extremity edema. The cardiorespiratory exam demonstrated normal heart sounds without mummers, rub, or gallops with clear lung sounds. The rest of the physical exam was unremarkable. Upon admission to the emergency department; a chest xray, set of cardiac enzymes, electrocardiogram was obtained. The initial studies were negative and the patient was scheduled for an ECHO which demonstrated an ejection fraction of $20 \%-25 \%$ with previous results of

*Correspondence: Bankim Patel; Email: bankim.pate119@gmail.com; Address: Ross University School of Medicine, Dominica, USA. 
$15 \%$. Additional findings include reduced systolic function consistent with a grade 2 diastolic dysfunction and diffuse hypokinesis. The coronary angiography and $\mathrm{CT}$ angiography demonstrated an aberrant malignant course of the left main coronary artery coming from the right coronary ostium and coursing between the aorta and pulmonary artery (see Figures 1,2$)$. The left ventricular dysfunction was thought to be a consequence of this malignant course. Due to the he course of the left main coronary artery, during times of increase cardiac work the artery would become compressed leading to the suspected chest pain and cardiomyopathy. Cardiothoracic surgery was consulted which determined the need for CABG. He underwent a double vessel bypass with a left internal mammary to the left anterior descending and a saphenous vein graft to the obtuse marginal branch of the circumflex.

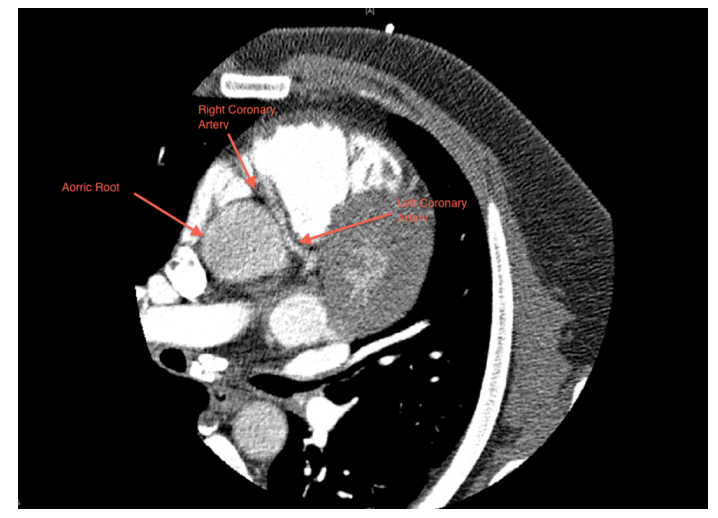

Figure 1. CTA Heart above illustrating an aberrant course initially originating from the right coronary cusp and coursing between the arch of aorta and the pulmonary arteries
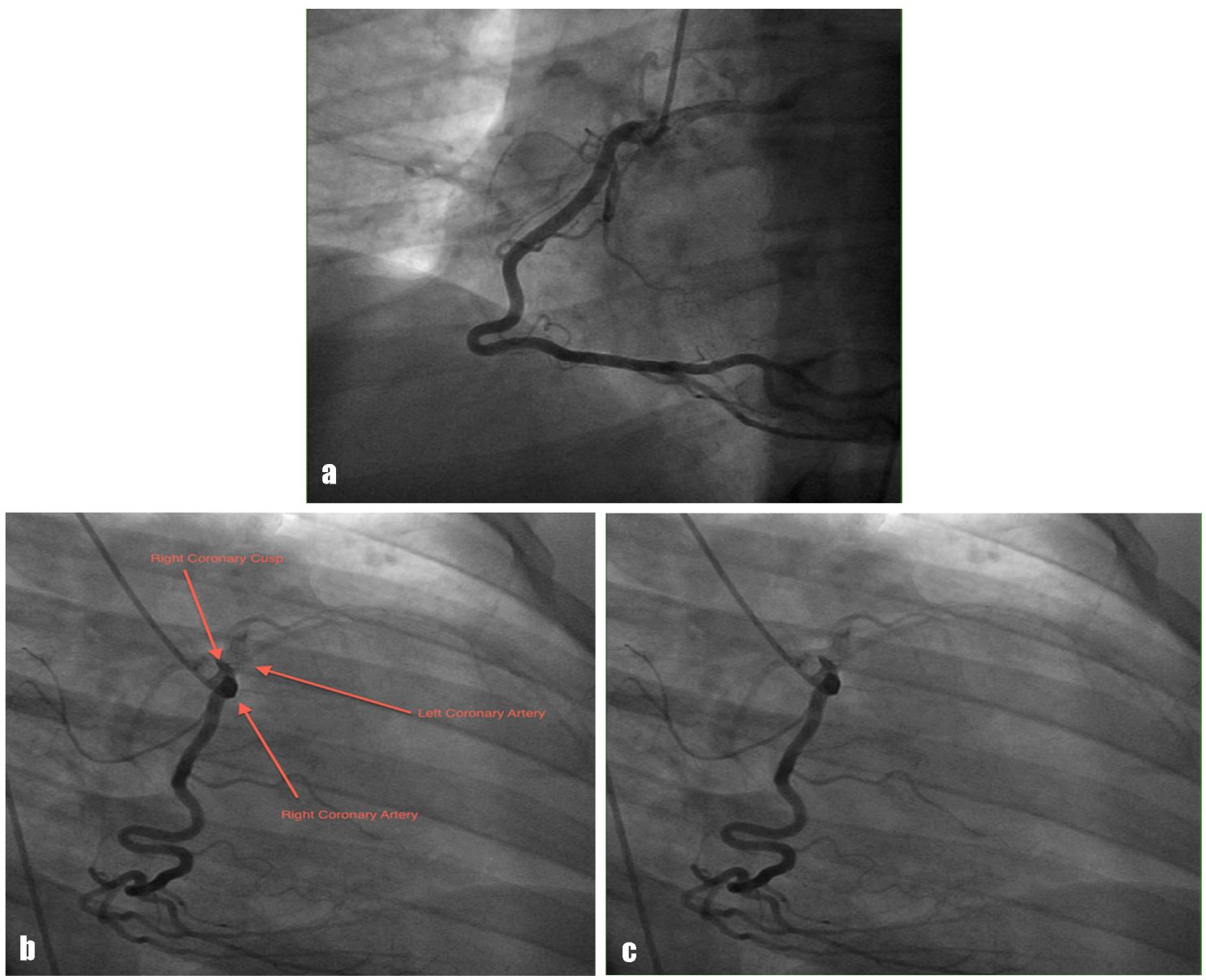

Figure 2. Coronary angiogram above illustrating the LCA arising from the right coronary cusp

\section{Discussion}

The discussion of coronary artery anomalies has transformed concerning the definition, clinical presentation, diagnostic workup, treatment, and prognosis with the emergence of improved imaging techniques and increased detection of these anomalies. Classification criteria of these arteries have been widely discussed and literature have attempted to classify as "major", "severe", "important", or hemodynamically significant versus minor ones; other groups have attempted to create a scheme based on the incidence of unselected general 
population. ${ }^{[1,2]}$ The incidence of coronary anomalies and patterns in a series of 1,950 angiograms was determined to be $5.64 \%$ with the left coronary artery (LCA) arising from the right sinus in $0.15 \%$ of the angiograms. ${ }^{[1]}$ Furthermore, abnormal courses of the left coronary artery have the most severe impact on cardiac function especially the interarterial course. The interartieral course represents the left coronary artery traveling between the aortic and pulmonary artery as in the case of our patient. The proposed mechanism for the LCA involves a compression of the artery by the aortic and pulmonary artery especially during severe exertion. ${ }^{[3]}$

A study determined that left coronary artery which provides blood flow to the free wall of the left ventricle resulted in cardiac death and no other coronary arteries anomalies resulted in the same consequence. ${ }^{[1]}$ Hemodynamically significant anomalies that lead to symptomatic manifestations include negative alterations of myocardial perfusion leading to increased risk of myocardial ischemia or sudden death. ${ }^{[4,5]}$ In addition, other cardiac symptoms can be presenting including dyspnea, palpitations, angina pectoris, dizziness, and syncope ${ }^{[1,6,7]}$ Finally, the patient can present with congestive heart failure progressing over a brief course of time. Upon literature review, isolated cases of LCA anomalies have been reported. ${ }^{[8,9]}$

Diagnostic approach to patients with coronary artery anomalies usually have patients with no clinical presentation for a large portion of their lives and then develop atypical chest pain, which is the referring reason for coronary angiography then to CT angiography. However, these patient populations can present with sudden cardiac death at a young age with extreme exertion. ${ }^{[1]}$ Specific attention should be given to especially for athletes and other young individuals subjected to extreme exertion. Other diagnostic modalities involve electrocardiogram monitoring to document atrial or ventricular arrhythmias; echocardiography can be utilized for identification of coronary artery anomalies and its proximal course. ${ }^{[10,11]}$ Surgical treatment is considered an appropriate recommendation for individual with anomalous left coronary artery due to the correlation of sudden cardiac death. ${ }^{[12]}$ In addition, surgical intervention is especially warranted when a large cardiac muscle region vulnerable to ischemia or infarction. Options include direct reimplantation of the ectopic artery at the aortic root or coronary artery bypass with either internal thoracic artery or saphenous venous graft. ${ }^{[1,12]}$ For intramural coronary arteries, an unroofing of the artery off the aortic wall from the ostium to the exit point is recommended or performing an osteoplasty at the endpoint of the intramural segment. ${ }^{[1]}$

\section{Conclusion}

Our case urges the clinician to expand the differentials diagnosis in young to middle age patient presenting with chest pain and new onset severe congestive heart failure. In addition, our case reinforces the concept of the detrimental impact of malignant left coronary arteries on cardiac function. The symptoms demonstrate how coronary artery anomalies can manifest into common presentations of cardiac conditions such as heart failure without systemic symptoms and typical chest pain. This should prompt the physician to consider coronary anomalies as a cause and base treatment on the patient's clinical status and medical history.

\section{CONFlicts OF INTEREST Disclosure}

The authors have declared no conflicts of interest.

\section{REFERENCES}

[1] Angelini P, Villason S, Chan AV, et al. Normal and anomalous coronary arteries in humans. In: Angelini P, ed. Coronary Artery Anomalies: A Comprehensive Approach. Philadelphia: Lippincott Williams \& Wilkins. 1999: 27-150.

[2] Angelini P, Velasco JA, Flamm S. Coronary anomalies: Incidence, pathophysiology and clinical relevance. Circulation. 2002; 105: 244954. PMid:12021235 http://dx.doi.org/10.1161/01.CIR.00 00016175.49835 .57

[3] Grollman JH Jr, Mao SS, Weinstein SR. Arteriographic demonstration of both kinking at the origin and compression between the great vessels of an anomalous right coronary artery arising in common with a left coronary artery from above the left sinus of Valsalva. Cathet Cardiovasc Diagn. 1992; 25: 46-51. http: //dx.doi.org/10.1002/ccd.1810250110

[4] Reagan K, Boxt LM, Katz J. Introduction to coronary arteriography. Radiology Clin North Am. 1994; 32: 419-33. PMid:8184022
[5] Abouzied AM, Amaram S, Neerukonda SK. Anomalous left coronary artery arising from right sinus of valsalva could be a minor congenital anomaly - a case report and review of the literature. Angiology. 1999; 50: 175-178. PMid:10063951 http://dx.doi.org/10.11 $77 / 000331979905000214$

[6] Liberthson RR, Dinsmore RE, Fallon JT. Aberrant coronary artery origin from the aorta: report of 18 patients, review of literature and delineation of natural history and management. Circulation. 1979; 59: 748-754. PMid:421315 http://dx.doi.org/10.1161/01.CIR. 59.4 .748

[7] Angelini P, Velasco JA, Ott D, et al. Anomalous coronary artery arising from the opposite sinus: descriptive features and pathophysiologic mechanisms, as documented by intravascular ultrasonography. J Invasive Cardiol. 2003; 15: 507-514. PMid:12947211

[8] Murphy DA, Roy DL, Sohal M, et al. Anomalous origin of the left main coronary artery from anterior sinus of valsalva with myocardial infarction. J Thorac Cardiovasc Surg. 1978; 75: 282-285. 
PMid:625134

[9] Basso C, Maron BJ, Corrado D, et al. Clinical profile of congenital coronary artery anomalies with origin from the wrong aortic sinus leading to sudden death in young competitive athletes. J Am Coll Cardiol. 2000; 35: 1493-501. http://dx.doi.org/10.1016/S07 35-1097 (00) 00566-0

[10] Gaither NS, Rogan KM, Stajduhar K, et al. Anomalous origin and course of coronary arteries in adults: identification and improved imaging utilizing transesophageal echocardiography. Am Heart J. 1991; 122: 69-75.
[11] Post JC, van Rossum AC, Bronzwaer JG, et al. Magnetic resonance angiography of anomalous coronary arteries: A new gold standard for delineating the proximal course? Circulation. 1995; 92(11): 3163-71. PMid:7586299 http://dx.doi.org/10.1161/01.CIR. 92.11 .3163

[12] Krasuski RA, Magyar D, Hart S, et al. Long-Term Outcome and Impact of Surgery on Adults With Coronary Arteries Originating From the Opposite Coronary Cusp. Circulation. 2011; 123: 154162. PMid:21200009 http://dx.doi.org/10.1161/CIRCULATI ONAHA . 109.921106 